Saru Arifin

\title{
ARTIFICIAL INTELLIGENCE IN THE WORKPLACE - HOW SHOULD MORAL AND LEGAL ISSUES BE ADDRESSED?
}

Saru Arifin, PhD student, Faculty of Law, University of Pécs, Hungary, saruarifin@mail.unnes.ac.id

Artificial Intelligence (AI) has emerged as a new method for efficiently and cost-effectively assisting human activities as science and technology have progressed in the fourth industrial revolution. It has been argued that Artificial Intelligence works in two ways. It can both create and eliminate jobs. Based on present technological capabilities, AI has sparked speculative discussions concerning its implications for morality and law. This article argues that AI is a technological advancement that will help businesses grow in the fourth industrial revolution. The controller determines its effects hence it can be put to either good or bad use. As a result, for AI to benefit the prosperity and well-being of humanity to the greatest degree, morals must be embedded in its use, and the law must be enacted to ensure that human commitment to using AI wisely in business processes is consistent.

Keywords:

Artificial Intelligence, economic development, job, law, morality 


\section{INTRODUCTION}

Artificial Intelligence describes a type of machine that was created as a result of recent technological advancements. Humans' desire to make work easier when there is a complex and complicated flow of information necessitates the creation of an instrument to simplify it, thereby simplifying the work of humans in corporations, governments and the military. In today's social life, accuracy and speed in making decisions are important. However, the presence of AI frequently sparks debate in society, focusing on moral and legal issues such as what AI is and how it operates, and the moral ${ }^{1}$ and legal boundaries that must be applied in its use ${ }^{2}$. These emerging technologies have a significant impact on the workforce, as evidenced by their rapid growth. Without a large number of employees, many large tech companies have still managed to achieve broad economies of scale. ${ }^{3}$

The ability of electronic computers to store large amounts of data and process it at high speeds posed a challenge to scientists who wanted to create systems that could mimic human abilities. Human skills and capabilities have been increasingly mastered and carried out by electronic machines since the 1950s. These capabilities have become more affordable for many people because of the development and popularisation of the personal computer. Computers with ever-increasing memory capacities, speed, reliability and robustness are now bringing artificially intelligent tools to desktops all over the world. ${ }^{4}$

Artificial Intelligence already allows machines to perform a variety of human tasks, such as driving cars and reacting to their environment, as well as providing virtual assistance and playing video games. ${ }^{5}$ Robots are already widely used in a variety of industries, and they are expected to spread to the consumer market in the coming years. According to some experts, the benefits of AI can also be employed in legal work. Even in the realm of justice, Crootof ${ }^{6}$ suggested that judges consider adopting AI in judicial work to benefit from technological advancements. Similarly, lawyers can use AI in their work. ${ }^{7}$ Cueller $^{8}$ has more concrete suggestions in this regard, such as adjusting the common law, which is based on historical judgment, to take advantage of AI's ability to record past cases,

Andrea Gilli, Massimo Pellegrino and Richard Kelly, 'Intelligent Machines and the Growing Importance of Ethics', in The Brain and the Processor: Unpacking the Challenges of Human-Machine Interaction (Rome: NATO Defense College, 2019), 44-54.

2 Liis Vihul, 'International Legal Regulation of Autonomous Technologies', in Modern Conflict and Artificial Intelligence, ed. by Allison Leonard (Waterloo, ON Canada: Centre for International Governance Innovation, 2020).

3 Darrell M West, 'What Happens If Robots Take the Jobs? The Impact of Emerging Technologies on Employment and Public Policy', Centre for Technology Innovation at Brookings, 26 October 2015.

4 Gabriel Hallevy, When Robots Kill. Artificial Intelligence under Criminal Law (Boston: Northeastern University Press, 2013).

Shanhong Liu, 'Artificial Intelligence (AI) Worldwide - Statistics \& Facts', Statista, 27 October 2021.

Rebecca Crootof, 'Cyborg Justice and the Risk of Technological-Legal Lock-In', Columbia Law Review Forum 119 (2019), 233-251.

Blair Janis, 'How Technology Is Changing the Practice of Law', GPSolo 31, no 3 (2014), 10-13.

Mariano Florentino Cuéllar, 'A Common Law for the Age of Artificial Intelligence', Columbia Law Review 119, no 7 (2019), 1773-1792. 
making it easier for the current judge to find bases for their argumentation from the past. Accordingly, William Henderson, ${ }^{9}$ a law Professor at Indiana University's Maurer School of Law, has argued that legal processing engineering has changed and will continue to change legal practice, necessitating the teaching of process engineering skills in law schools.

Additionally, AI is increasingly being employed to aid government and private sector employees. In fact, many decisions that were previously made by humans are increasingly being delegated to automated AI systems. ${ }^{10}$ In Europe, the use of Artificial Intelligence (AI) technologies by doctors was still uncommon in 2020. According to Statista, ${ }^{11}$ only $5 \%$ of European clinicians who responded used AI. However, the use of AI appeared to be slightly higher in Germany and Denmark, where 7\% of clinicians stated that they use the technology. On the other hand, only $2 \%$ of doctors surveyed said they use AI. In terms of AI implementation, Portugal lags behind the European average.

Despite its benefits to economic development, the arrival of AI has not only sparked debate in the workplace, but also in the legal field, where debates have erupted over whether AI can be classified as a legal subject, allowing it to be held accountable for crimes, for example. The following is a critical question posed by the European Parliament: ${ }^{12}$

Finally, robot autonomy raises the question of their nature in light of existing legal categories - whether they should be considered natural persons, animals, or objects - or whether a new category should be created, with its own unique features and implications for the attribution of rights and duties, including liability for damage.

When a self-contained system is given legal personhood, it creates a situation which can help answer questions about meaningful control. However, dealing with legal personhood ${ }^{13}$ in the context of autonomous systems is difficult and presents new challenges. Who determines which systems are capable of being treated as legal entities? How should this be done, and under what circumstances? What happens if the system is turned off and no longer functions? ${ }^{14}$ As a result, legal experts continue to track the progress of Artificial Intelligence, which is still being developed by experts in its related fields. Meanwhile, legal academics see the AI issue as requiring a code of ethics that should serve as a guide for

$9 \quad$ Kevin D Ashley, Artificial Intelligence and Legal Analytics. New Tools for Law Practice in the Digital Age (London - New York: Cambridge University Press, 2017).

10 Yifat Nahmias and Maayan Perel, 'The Oversight of Content Moderation by AI: Impact Assessments and Their Limitations', Harvard Journal on Legislation 58, no 1 (2021), 145-194.

11 Liu, 'Artificial Intelligence'.

12 Liisa Janssens, 'A Prospect of the Future. How Autonomous Systems May Qualify as Legal Persons', in Being Profiled, ed. by Emre Bayamlioglu, Irina Baraliuc, Lisa Janssens and Mireille Hildebrandt (Amsterdam: Amsterdam University Press, 2019), 116-121.

13 The philosophical discussion of what constitutes a person can be read in Visa A J Kurki and Tomasz Pietrzykowski, Legal Personhood: Animals, Artificial Intelligence and the Unborn (Cham: Springer).

14 Janssens, 'A Prospect of the Future', 117. 
AI users. ${ }^{15}$ The various parties' ideas about an AI code of ethics are embodied in various models of a code of conduct, including those developed by the OECD, Canada, China and the United Nations for military AI. ${ }^{16}$

This article will discuss the use of artificial intelligence in the workplace from a moral and legal perspective. The structure of this article is as follows: the first section discusses the context for this article. The next section will address AI and its applications, and outline the essential principles of AI from experts in respective disciplines. Following that, there will be a discussion regarding the economic benefits of artificial intelligence. The next section will discuss the moral dilemma that occurs when AI is used, as well as how the law may help regulate AI use and keep it on track with the concept and context of AI development. The article concludes with a discussion on how to balance moral and legal concerns around the use of AI in corporate activity.

\section{A BRIEF UNDERSTANDING OF AI}

Understanding the definition of AI correctly will help in understanding AI in its context and avoid making erroneous conclusions about AI and its implications. There is a plethora of definitions and typologies of what constitutes Artificial Intelligence. In most applications, however, AI is defined as non-human intelligence that can replicate human mental skills such as pattern recognition, understanding natural language, adaptive learning from experience, strategising or reasoning about others. ${ }^{17}$ From this definition of intelligence, which involves internal (computation) processes, which serve external results (the ability to achieve goals) in a complex, dynamic environment (in the world), we can proceed to Artificial Intelligence definition. ${ }^{18}$

Artificial Intelligence (AI) is a branch of computer science that has captivated people's imaginations and has been the subject of science fiction films for decades. AI refers to the development of intelligent hardware or software that can mimic human behaviours such as learning and problem solving. ${ }^{19}$ Although it was coined as a technical term by a Stanford Professor, John McCarthy, in 1956, ${ }^{20}$ it has since become a commonplace expression, frequently depicted in films by robots who act like humans in a variety of situations and stories - from robots overthrowing their human masters to societies where robots and

15 Stephan De Spiegeleire, Matthijs Maas and Tim Sweijs, What Is Artificial Intelligence? (The Hague Centre for Strategic Studies, 2017).

16 Maya Medeiros, 'Public and Private Dimensions of AI Technology and Security', in Modern Conflict and Artificial Intelligence, ed. by Allison Leonard (Waterloo, ON Canada: Centre for International Governance Innovation, 2020), 20-25.

17 Spiegeleire et al., What Is Artificial Intelligence?, 42.

8 Ibid.

19 Liu, 'Artificial Intelligence'.

20 Stuart C Shapiro, 'Artificial Intelligence', in Encyclopedia of Computer Science, ed. by Edwin D Reilly, David Hemmendinger and Anthony Ralston (New York: Wiley, 1991), 1-9. 
humans coexist. Artificial Intelligence is no longer a science fiction concept, it has become a part of people's daily lives.

Machine learning is a subset of Artificial Intelligence which is widely used in computer science. However, the concept of learning in this context is not the same as high-order thinking in humans, because AI regularly relies on human teaching for specific thinking. ${ }^{21}$ In other words, $\mathrm{AI}$ is more knowledgeable in the areas of thought that it receives from humans on a regular basis. ${ }^{22}$ To summarise, Agrawal $^{23}$ claims that machine learning does not imply an increase in artificial general intelligence capable of replacing humans in all aspects of cognition, but rather the development of one specific aspect of intelligence: prediction. In this scenario, AI is unable to accomplish anything other than what its controller desires. As a result, the AI's effort is constrained to a single objective that the controller has determined.

\section{AI IMPACT ON FUTURE ECONOMIC DEVELOPMENT AND JOBS}

Artificial Intelligence is a burgeoning field of computer science with practically limitless applications. By 2023, the global AI market is expected to be worth 97.9 billion dollars. Artificial Intelligence is attracting interest from businesses, particularly those in the software and IT services industries. Simultaneously, AI-focused startups have grown in popularity and seen great investor interest, nearly tripling in funding between 2015 and 2018. Machine learning is a type of Artificial Intelligence that allows computers to learn without the need for human intervention, and this is the focus of the majority of AI startup companies. At least $\$ 31.7$ billion has been invested in this area of Artificial Intelligence. Many startups have also invested in the field of natural language processing, which includes voice and speech recognition as well as text prediction. ${ }^{24}$

The impact of AI on future economic development and job creation will be discussed in this section. Is AI having a positive impact on both the economy and jobs, or is it only having a positive impact on the economy and not on jobs, or will AI have a negative impact on jobs?

${ }_{21}$ Maria Stefania Cataleta, 'The Fragility of Human Rights Facing AI', Humane Artificial Intelligence, Working Paper, no 2 (2020).

22 Spiegeleire et al., What Is Artificial Intelligence?, 42.

23 Ajay Agrawal, Joshua S Gans and Avi Goldfarb, 'Artificial Intelligence: The Ambiguous Labor Market Impact of Automating Prediction', Journal of Economic Perspectives 33, no 2 (2019), 31-50.

24 Liu, 'Artificial Intelligence'. 


\subsection{AI impact on economic activities}

AI will be used as a tool to help firms operate in the future model of business life. According to Bughin, ${ }^{25}$ around $70 \%$ of businesses will be using at least one of these types of AI technologies by 2030, while less than half of large businesses will be utilising the full range of AI technologies across their organisations. In the aggregate, and bearing in mind that netting can help economic entities mitigate competition effects and transition costs, AI could deliver an additional $\$ 13$ trillion in economic output by 2030 , boosting global GDP by about $1.2 \%$ per year.

Businesspeople, particularly in Europe, are hoping that Artificial Intelligence (AI) will improve their bottom line. This is demonstrated by the statistic in Figure 1 regarding the future impact of Artificial Intelligence (AI) on the jobs of European advertising professionals. According to the survey, $62 \%$ of industry professionals expected AI to free up more time for strategic decision-making and reduce repetitive processes. ${ }^{26}$ Moreover, the impact of AI on the labour market is expected to be greatest among workers with advanced skills in the field of information technology. Between 2016 and 2022, the number of high-skilled service workers in the United States is expected to rise from 690,000 to 1 million. Meanwhile, in Asia, India and the Philippines are two of the most important countries in terms of recruiting high-skilled labour, whereas in Europe, the United Kingdom is the leader in this area. ${ }^{27}$

These figures demonstrate two crucial aspects of future business growth. The first is that, thanks to Artificial Intelligence, the business world will become more productive and dynamic. ${ }^{28}$ As a result, in the future, a typical business will require a large number of workers with information technology skills. This situation necessitates a significant shift in the focus of tertiary institutions, which must now require graduates to possess technological skills in addition to knowledge. This finding sends a strong signal to universities, suggesting that they should use AI to rethink their programs. Academic competence alone will not prepare future graduates to compete in the work market. Both theoretical grasp and technological ability will be critical. To realise this vision, however, a debate about AI as a technological breakthrough must be initiated, which would ascertain the most appropriate location for

25 Jacques Bughin et al., 'Modeling the Global Economic Impact of AI', McKinsey Global Institute, 04 September 2018.

26 IAB Europe, 'Opinion of advertising professionals on how Artificial Intelligence (AI) will impact their jobs in Europe 2018', Statista, 11 July 2018.

27 HfS Research, 'Change of IT/business processing outsourcing (BPO) high-skilled service worker numbers due to automation and AI, from 2016 to 2022, by select country (in millions)', Statista, 30 August 2017.

28 Jason Furman and Robert Seamans, 'AI and the Economy', Innovation Policy and the Economy 19, no 1 (2019), 161-191. 
AI as a cultural component ${ }^{29}$ to be included in the curriculum ${ }^{30}$ or to establish its lack of relevance.

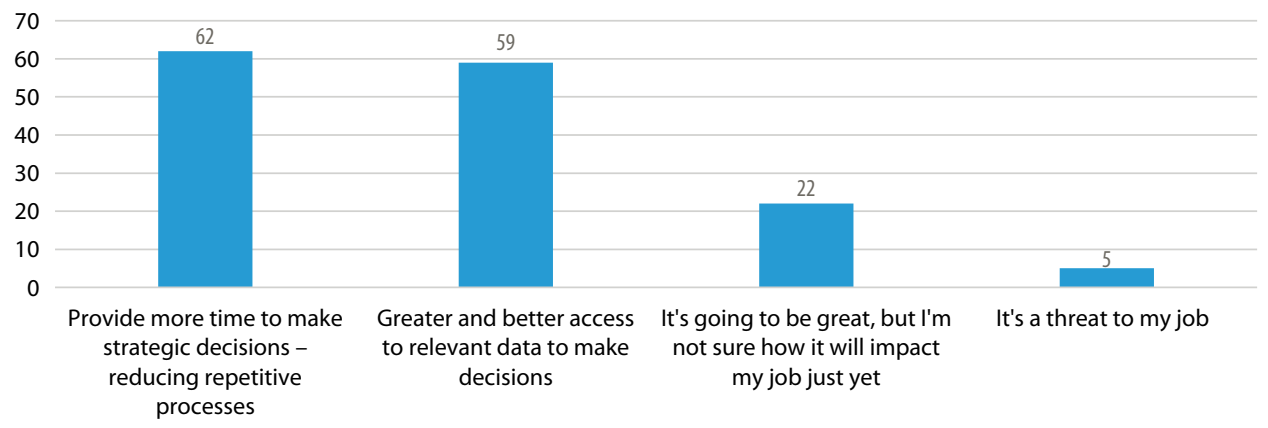

Figure 1 - Opinions of advertising professionals on how AI will change their jobs Source: IAB Europe, 'Opinion of advertising professionals'.

What fields of work will AI have a direct impact on? The results of a study ${ }^{31}$ conducted in China in 2017 and the conclusions drawn by its authors may shed some light on this. The net impact of Artificial Intelligence (AI) and related technologies on the percentage of jobs created or displaced in China between 2017 and 2037 was calculated, broken down by sector. AI and related technologies are expected to create around $29 \%$ of service sector jobs in China by 2037, according to the projections of the study. Meanwhile, Trajtenberg ${ }^{32}$ believes that the healthcare and education sectors will account for the majority of future job growth. The impact of AI on employment is not certain, but it is likely to be ephemeral. The most important factor will continue to be demand by companies. Although it is true that Artificial Intelligence (AI) will automate many jobs, its overall impact on employment is unclear. In recent decades, technological advancements have resulted in a significant reduction in manufacturing jobs. Prior to that, employment levels grew for over a century, even in industries undergoing rapid technological change. What went wrong? At first, demand was highly elastic, but then it became inelastic. Artificial Intelligence's impact on jobs will be similarly influenced by the nature of the demand for labour. ${ }^{33}$

29 José Felix Angulo Rasco, 'In Search of the Lost Curriculum', Counterpoints 491 (2016), 137-155.

30 Radhika Santhanam and Marc J Schniederjans, 'Artificial Intelligence: Implications for Teaching Decision Science', Interfaces 21, no 5 (1991), 63-69. See also Bob L Taylor et al., 'Computer Use in Curriculum Development and Curriculum Management', Educational Technology 29, no 4 (1989), 49-51.

$31 \quad \mathrm{PwC}$, 'Estimated net impact on share of jobs displaced or created by Artificial Intelligence and related technologies in China between 2017 and 2037, by sector', Statista, 18 September 2018.

32 Manuel Trajtenberg, 'AI as the Next GPT: A Political-Economy Perspective', NBER Working Paper, no 24245 (2018).

33 James Bessen, 'AI and Jobs: The Role of Demand', NBER Working Paper, no 24235 (2018). 


\subsection{AI impact on jobs}

The data illustrated in Figure 2 appears to refute the belief held by many that the presence of AI will have a negative impact on the world of work. Predicting the situation in 2022, this is an estimate of the number of jobs that will have been created and lost due to Artificial Intelligence (AI) by that time. By 2022, it is estimated that 2.3 million jobs will have been created and 1.8 million lost due to AI. This data supports the CEOs' belief in AI's positive impact on job creation. According to Martin Armstrong, ${ }^{34}$ most of the latter (63\%) believe that the AI revolution will have a greater impact on the world than the Internet revolution, with about one out of every five CEOs being extremely convinced of this. Business leaders in general, on the other hand, are split on how this technology will affect the labour market. $41 \%$ of them believe that AI will eliminate more jobs than it creates, while only $49 \%$ believe the opposite.

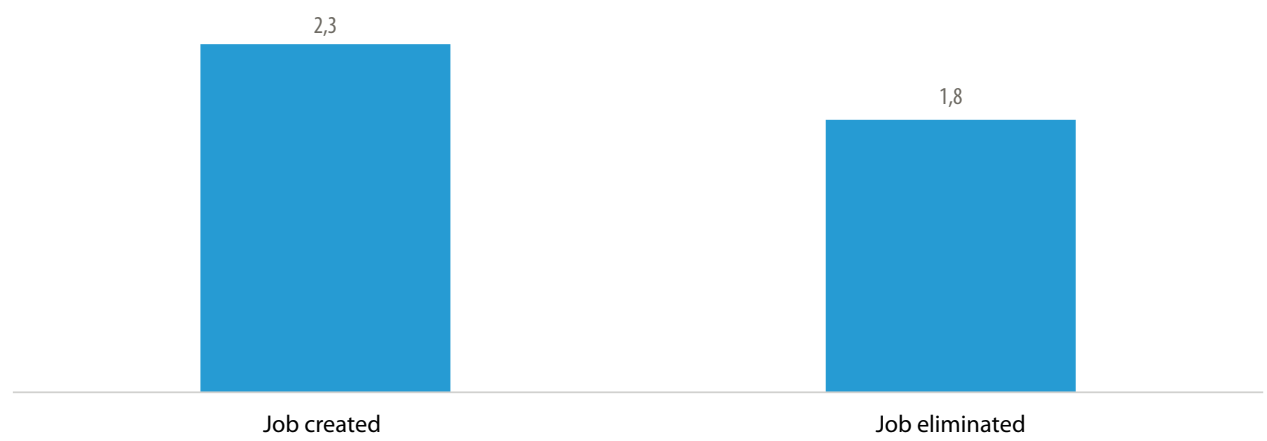

Figure 2 - The number of jobs created and eliminated due to Artificial Intelligence (AI) worldwide in 2022 (in millions)

Source: Gartner, 'The number of jobs created'.

It is significant that most of the new jobs created will be technology-based. As a result, workers with qualifications that are compatible with the requirements of operating AI will be in high demand. Jobs that are replaced by Artificial Intelligence, on the other hand, will be lost. Accordingly, AI will have a negative impact on workers who do not have a background in information technology that is compatible with AI's requirements. Workers who lack technological knowledge and skills will also be excluded from the pool of candidates. This prediction is supported by the preceding data. According to a 2019 survey of Italian employees, the results of which are shown in Figure 3, the majority of workers believed that Artificial Intelligence would soon affect the way they performed their daily tasks. Employees in Italy were generally optimistic when asked about the potential impact of Artificial Intelligence (AI) or automation on their jobs. In fact, nearly seven out of ten

34 Martin Armstrong, 'A.I. Revolution: What Do Business Leaders Think?', Statista, 23 January 2019. 
respondents thought AI could help them be more efficient at work. Only $8.36 \%$ of those polled were concerned that Artificial Intelligence or automation would render their jobs obsolete. $^{35}$

Employees already know and understand that AI will become an important tool in the business processes in which they work, according to this data. Workers are aware of this, despite not knowing the technical details of how AI is used in the company where they work. They have, however, prepared for the arrival of AI. The company has completed a small part of the process by providing training tailored to the company's AI operational needs.

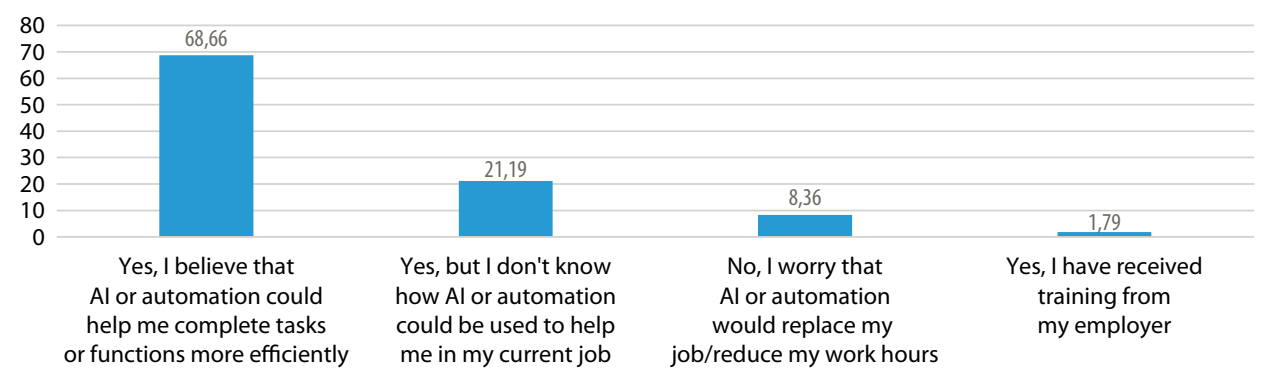

Figure 3 • Employee's opinion on how AI will affect their jobs in Italy 2019

Source: Docebo, 'If Artificial Intelligence or automation'.

The introduction of AI is unavoidable, especially in today's increasingly competitive business environment. Instead of recruiting new personnel or laying off employees who lack information technology skills, established companies prefer to prepare their employees for this transition by providing them with the skills that AI requires. This is also an area where corporate social responsibility appears to have played a beneficial role.

\section{AI AND LEGAL ROLES: AN ETHICAL CONFLICT}

Employees and employers sometimes make hasty conclusions about what Artificial Intelligence means, presuming that AI will have a negative effect on the future of the world of work. ${ }^{36}$ There is a perception that AI replaces human labour with robots, which will lead to unemployment, particularly among recent university graduates in various countries. To avoid misunderstandings about what AI means and the scope of AI's operation, it is necessary to address this in detail. However, whether AI will be abused to further

35 Docebo, 'If Artificial Intelligence or automation (i.e. automating functions of certain jobs or daily tasks) is introduced into your workplace, do you think it would have a positive impact on your job?', Statista, 25 June 2019.

36 Spiegeleire et al., What Is Artificial Intelligence?, 35. 
economic interests and increase the efficiency of a corporation or government institution does not need to be explained in terms of AI as such. The answer to this depends instead on the morality of the business owner or government institution concerned. If the context for which AI was created and intended is consistent, then such abuses can be avoided. On the other hand, if business leaders or the heads of state bodies only think in terms of economics and efficiency, AI will likewise become an instrument for achieving these objectives.

To provide legal certainty on moral dilemmas in the workplace the law must define clear boundaries as to the scope and purpose of AI, and establish which limits should not be violated by AI users. Although a Code of Ethics for the application of AI may be sufficient to counteract those who only consider the benefits that they might derive from misusing AI, positive laws also need to be adopted. For example, a company may wish to make a great profit at a low cost in a field which traditionally absorbs a lot of labour, by using robots, which can only be controlled by a few people who are experts on the robot and its work, thus avoiding the need to employ many people. Then the moral question is: what is the moral responsibility of the company for the unemployment this would lead to, and how should it support unemployed families, and contribute to the welfare mean of the community?

Reflecting on the above example of the misuse of AI, a code of ethics does not adequately safeguard the morality of AI use. Instead, a law is needed that provides its users with clear guidelines for fitting into the context for which $\mathrm{AI}$ is intended. AI is intended by its creators only to help people make complicated and complex problems simple and easy, so that they can support human productivity better, more efficiently and faster. According to the mission statement of the IEEE Global Initiative on the Ethics of Autonomous and Intelligent Systems, ${ }^{37}$ the organisation's goal is to "ensure that every stakeholder involved in the design and development of autonomous and intelligent systems is educated, trained, and empowered to prioritize ethical considerations so that these technologies are advanced for the benefit of humanity".

As a result, in the business world particularly, several legal principles can be normalised into legal rules regarding AI. First, the intent and purpose of AI must be clearly stated in the rules for its use. The goal of AI is to assist, not to replace. ${ }^{38}$ This statement must be made from the outset to provide clear directions to future AI users. As a result, there is no risk of AI being misused in business. Second, the rules for using AI must be emphasised in terms of the characteristics of AI-enabled jobs. The regulation of the limits of the tasks carried out by AI is necessary to ensure that AI does not replace all human labour and that society does not experience mass unemployment. This limitation can also apply to the proportion of human labour and AI that can be mathematically negotiated between the government as the regulator and businesspeople, or between the government with

Medeiros, 'Public and Private Dimensions', 23.

38 Edwina L Rissland, 'Artificial Intelligence and Law: Stepping Stones to a Model of Legal Reasoning, The Yale Law Journal 99, no 8 (1990), 1957-1981. 
the people's representatives as representatives of society. Agrawal's ${ }^{39}$ research reveals clear boundaries in the scope of the work of AI, especially regarding predictions that are dependent on decisions taken by workers or company owners who set AI the task of making predictions. Accordingly, he believes that AI will not necessarily replace workers' jobs, but that workers' skills will need to be adjusted to facilitating the predictions required by AI for AI to assist in bettering the work or production of a company. Third, in the legal rules governing the use of $\mathrm{AI}$, the way that the rules will be enforced must be made clear. To ensure accountability for the use of AI in business, supervision is required. Fourth, strict penalties for the misuse of AI must be defined and imposed, considering the negative consequences of such malpractice.

Given each country's unique work culture, the legal rules that govern AI use must be established in the form of a convention resulting from a global consensus. The Organization for Economic Co-operation and Development (OECD) has developed AI principles to promote trustworthy AI that respects human rights and democratic values, for example. The "OECD AI Principles", formally known as the Council on Artificial Intelligence Recommendation, were adopted by OECD member countries in May 2019 and are the first such principles to be signed by governments. ${ }^{40}$ This convention can be adapted by each country to fit its own national legal system, depending on the context and legal system in place in that country. To this end, several "foreign governments have proposed national AI policies or policies that purport to regulate some aspect of the adjacent technology stack", in addition to international principles. The National Cyber Security Strategy of Canada outlines a vision for safeguarding Canadians' digital privacy, security and economy, as well as a commitment to working with France on ethical AI. Another initiative, GB/T 35273-2020, or the "Information Security Technology-Personal Information Security Specification", is a Chinese national recommended standard for personal data collection. ${ }^{41}$ However, the EU stands out in this regard. They argue that because AI is currently viewed as nothing more than a tool in the hands of human agents, civil law, such as product liability rules, already apply to it. ${ }^{42}$

As has been argued above, AI should be able to improve humanity's welfare and prosperity as a whole, rather than just the subjective economic interests of a few individuals or institutions. As Rubin ${ }^{43}$ argues, if the machine is programmed to replace human power, we will be doomed to extinction as a species. As a result, as AI becomes more powerful, the number of jobs for which human workers are competitive may decrease, potentially increasing inequality and lowering the quality of our economy and lives. Alternatively, our society could recognise that there are sufficient resources, enough work to be done, and

\footnotetext{
Agrawal et al., 'Artificial Intelligence', 32.

Medeiros, 'Public and Private Dimensions', 22.

Ibid. 23.

2 Dennis J Baker and Paul H Robinson (eds), Artificial Intelligence and the Law. Cybercrime and Criminal Liability (London - New York: Routledge, 2021), LIX.

43 Charles T Rubin, 'Artificial Intelligence and Human Nature', The New Atlantis 1 (2003), 88.
} 
willing workers. We could adopt a strategy of allocating resources to create jobs that are not currently justified by increased shareholder profits but which will improve the quality of life in our society. In this vein, Smith ${ }^{44}$ warns that increased income inequality and mass unemployment could cause social unrest if we are not careful.

\section{CONCLUSION}

Scientific advancement requires the adoption of $\mathrm{AI}$ as a cutting-edge invention in information technology. Thus far, AI has been successful in speeding up and simplifying the handling of the complex data and information required by a wide variety of tasks, notably in the commercial world. To avoid the myriad services provided by AI being misapplied in profit-driven corporate activities, however, a code of ethics and legality for the use of AI must be created explicitly and forcefully. Professional and comprehensive independent monitoring is essential to ensure that business persons comply with the law while implementing AI in their commercial activity. In today's increasingly competitive business environment, the possibilities for applying $\mathrm{AI}$ in the corporate sector are almost limitless. As a result, embedding an ethics code for the use of AI in company operations is insufficient; the law governing the use of AI, specifically regulations addressing the various sorts of labour that may or may not be automated should be clearly regulated. Similarly, punishments against businesspeople that break a law's boundaries on the use of AI must be set firmly. Along with incorporating international standards into the development of legal laws governing the use of AI, it is critical to solicit input from a variety of stakeholders, while also taking into account each country's specific corporate, cultural and legal characteristics. Thus, moral and legal dilemmas associated with the use of AI can be resolved through a legally binding agreement made by all parties interested in AI, including businesses, government officials and community leaders.

44 Janna Anderson and Aaron Smith, 'AI, Robotics, and the Future of Jobs Key Findings', Technology Review 16, no 4 (2014), 28-35. 


\section{REFERENCES}

1. Agrawal, Ajay, Joshua S Gans and Avi Goldfarb, 'Artificial Intelligence: The Ambiguous Labor Market Impact of Automating Prediction'. Journal of Economic Perspectives 33, no 2 (2019), 31-50. Online: https://doi.org/10.1257/jep.33.2.31

2. Anderson, Janna and Aaron Smith, 'AI, Robotics, and the Future of Jobs Key Findings'. Technology Review 16, no 4 (2014), 28-35.

3. Armstrong, Martin, 'A.I. Revolution: What Do Business Leaders Think?' Statista, 23 January 2019. Online: www.statista.com/chart/16757/ceo-survey-impact-of-ai/

4. Ashley, Kevin D, Artificial Intelligence and Legal Analytics. New Tools for Law Practice in the Digital Age. London - New York: Cambridge University Press, 2017. Online: https://doi.org/10.1017/9781316761380

5. Baker, Dennis J and Paul H Robinson (eds), Artificial Intelligence and the Law. Cybercrime and Criminal Liability. London - New York: Routledge, 2021. Online: https://doi.org/10.4324/9780429344015

6. Bessen, James, 'AI and Jobs: The Role of Demand'. NBER Working Paper, no 24235 (2018). Online: https://doi.org/10.3386/w24235

7. Bughin, Jacques, Jeongmin Seong, James Manyika, Michael Chui and Raoul Joshi, 'Modeling the Global Economic Impact of AI'. McKinsey Global Institute, 04 September 2018. Online:www.mckinsey.com/featured-insights/artificial-intelligence/notes-fromthe-ai-frontier-modeling-the-impact-of-ai-on-the-world-economy

8. Cataleta, Maria Stefania, 'The Fragility of Human Rights Facing AI'. Humane Artificial Intelligence, Working Paper, no 2 (2020).

9. Crootof, Rebecca, 'Cyborg Justice and the Risk of Technological-Legal Lock-In'. Columbia Law Review Forum 119 (2019), 233-251.

10. Cuéllar, Mariano Florentino, 'A Common Law for the Age of Artificial Intelligence'. Columbia Law Review 119, no 7 (2019), 1773-1792.

11. De Spiegeleire, Stephan, Matthijs Maas and Tim Sweijs, What Is Artificial Intelligence? The Hague Centre for Strategic Studies, 2017.

12. Docebo, 'If Artificial Intelligence or automation (i.e. automating functions of certain jobs or daily tasks) is introduced into your workplace, do you think it would have a positive impact on your job?' Statista, 25 June 2019. Online: www.statista.com/ statistics/1040031/opinion-on-how-ai-will-change-jobs-in-italy/

13. Furman, Jason and Robert Seamans, 'AI and the Economy'. Innovation Policy and the Economy 19, no 1 (2019), 161-191. Online: https://doi.org/10.1086/699936

14. Gartner, 'The number of jobs created and eliminated due to Artificial Intelligence (AI) worldwide in 2022 (in millions)'. Statista, 13 December 2017. Online: www.statista. com/statistics/791992/worldwide-jobs-creation-elimination-due-to-ai/

15. Gilli, Andrea, Massimo Pellegrino and Richard Kelly, 'Intelligent Machines and the Growing Importance of Ethics', in The Brain and the Processor: Unpacking the Challenges of Human-Machine Interaction, ed. by Andrea Gilli. Rome: NATO Defense College, 2019, 44-54. 
16. Hallevy, Gabriel, When Robots Kill. Artificial Intelligence under Criminal Law. Boston: Northeastern University Press, 2013.

17. HfS Research, 'Change of IT/business processing outsourcing (BPO) high-skilled service worker numbers due to automation and AI, from 2016 to 2022, by select country (in millions)'. Statista, 30 August 2017. Online: www.statista.com/statistics/757223/ worldwide-impact-of-automation-ai-on-it-bpo-service-high-skilled-workers/

18. IAB Europe, 'Opinion of advertising professionals on how Artificial Intelligence (AI) will impact their jobs in Europe 2018'. Statista, 11 July 2018. Online: www.statista. com/statistics/880717/ad-industry-opinion-on-how-ai-will-change-jobs-in-europe/

19. Janis, Blair, 'How Technology Is Changing the Practice of Law'. GPSolo 31, no 3 (2014), $10-13$.

20. Janssens, Liisa, 'A Prospect of the Future. How Autonomous Systems May Qualify as Legal Persons', in Being Profiled, ed. by Emre Bayamlioglu, Irina Baraliuc, Lisa Janssens and Mireille Hildebrandt. Amsterdam: Amsterdam University Press, 2019, 116-121. Online: https://doi.org/10.1515/9789048550180-022

21. Kurki, Visa A J and Tomasz Pietrzykowski (eds), Legal Personhood: Animals, Artificial Intelligence and the Unborn. Cham: Springer. Online: https://doi.org/10.1007/978-3319-53462-6

22. Liu, Shanhong, 'Artificial Intelligence (AI) Worldwide - Statistics \& Facts'. Statista, 27 October 2021. Online: www.statista.com/topics/3104/artificial-intelligence-ai-world wide/

23. Medeiros, Maya, 'Public and Private Dimensions of AI Technology and Security', in Modern Conflict and Artificial Intelligence, ed. by Allison Leonard. Waterloo, ON Canada: Centre for International Governance Innovation, 2020, 20-25.

24. Nahmias, Yifat and Maayan Perel, 'The Oversight of Content Moderation by AI: Impact Assessments and Their Limitations'. Harvard Journal on Legislation 58, no 1 (2021), 145-194.

25. PwC, 'Estimated net impact on share of jobs displaced or created by Artificial Intelligence and related technologies in China between 2017 and 2037, by sector'. Statista, 18 September 2018. Online: www.statista.com/statistics/970960/chinaestimated-net-impact-on-share-of-job-by-ai-and-related-technologies-by-sector/

26. Rasco, José Felix Angulo, 'In Search of the Lost Curriculum'. Counterpoints 491 (2016), 137-155.

27. Rissland, Edwina L, 'Artificial Intelligence and Law: Stepping Stones to a Model of Legal Reasoning'. The Yale Law Journal 99, no 8 (1990), 1957-1981. Online: https:// doi.org/10.2307/796679

28. Rubin, Charles T, 'Artificial Intelligence and Human Nature'. The New Atlantis 1 (2003), 88-100.

29. Santhanam, Radhika and Marc J Schniederjans, 'Artificial Intelligence: Implications for Teaching Decision Science’. Interfaces 21, no 5 (1991), 63-69. Online: https://doi. org/10.1287/inte.21.5.63 
30. Shapiro, Stuart C, 'Artificial Intelligence', in Encyclopedia of Computer Science, ed. by Edwin D Reilly and David Hemmendinger and Anthony Ralston. New York: Wiley, 1991, 1-9.

31. Taylor, Bob L, Dennis W Cole, Myrle E Hemenway and Gary L Hillman, 'Computer Use in Curriculum Development and Curriculum Management'. Educational Technology 29, no 4 (1989), 49-51.

32. Trajtenberg, Manuel, 'AI as the Next GPT: A Political-Economy Perspective'. NBER Working Paper, no 24245 (2018). Online: https://doi.org/10.3386/w24245

33. Vihul, Liis, 'International Legal Regulation of Autonomous Technologies', in Modern Conflict and Artificial Intelligence, ed. by Allison Leonard. Waterloo, ON Canada: Centre for International Governance Innovation, 2020. Online: www.cigionline.org/ articles/international-legal-regulation-autonomous-technologies/

34. West, Darrell M, 'What Happens If Robots Take the Jobs? The Impact of Emerging Technologies on Employment and Public Policy'. Centre for Technology Innovation at Brookings, 26 October 2015, 1-22. 
Saru Arifin is a PhD candidate at the Faculty of Law, the University of Pécs, Hungary. From 2009 till the present, he has been teaching at the Faculty of Law, Universitas Negeri Semarang, Indonesia. His areas of study interest include Public International Law, Human Rights Law, and Legislation. 